\title{
ARE THREE MINUTES OF THE BASIC CARDIOPULMONARY RESUSCITATION A GREAT EFFORT FOR THE LAYPERSON?
}

López-González $A^{(1)(*)}$, Villada-Molina $E^{(1)}$, Carrión-Varela $\mathrm{M}^{(2)}$, López-Tendero $\mathrm{J}^{(2)}$, Ramirez-Tercero $\mathrm{A}^{(2),}$ Rabanales-Sotos $\mathrm{JA}^{(1)}$

(1) Nursing Faculty of the Albacete. University of Castilla-La Mancha (UCLM), (2) University Hospital of Albacete, Spain. (*) angel.lopez@uclm.es

\section{BACKGROUND}

The CPR Guidelines recommended that the rescuer is replaced every minute. However, it is difficult in the first moments to carry out the relays with such cadence and, therefore, it may be necessary to prolong the CPR time of each rescuer. Physical fatigue has a significant effect on the quality of external chest compressions (ECC), which can decrease after as few as 1-5 $\mathrm{min}$ of CPR. Percentage or maximal heart rate (\%RMHR) and effort perception (EP) were parameters usually analysed to evaluate the effort of the rescuer during CPR.

\section{AlMS}

The aims of this study were to analyse college students while they performed CPR on a manikin for three minutes, the following: 1) the optimal cut-off points of arms muscle strength to perform adequate ECC, 2) physiological response (\%RMHR), and 3) the PE.

\section{METHODS}

Quasi-experimental study involving one hundred and twenty-five subjects. We determined the body mass index, arms muscle strength (handgrip) and EP. Participants performed three minutes of CPR on a manikin. The study protocol was approved according to the Helsinki declaration.

\section{RESULTS}

1. The corresponding area under the receiver operating characteristic curves (ROC) to predicted adequate ECC for muscle strength were 0.561 . The best cut-off points for predicting successful ECC were $21.75 \mathrm{~kg}$ for handgrip dynamometry.

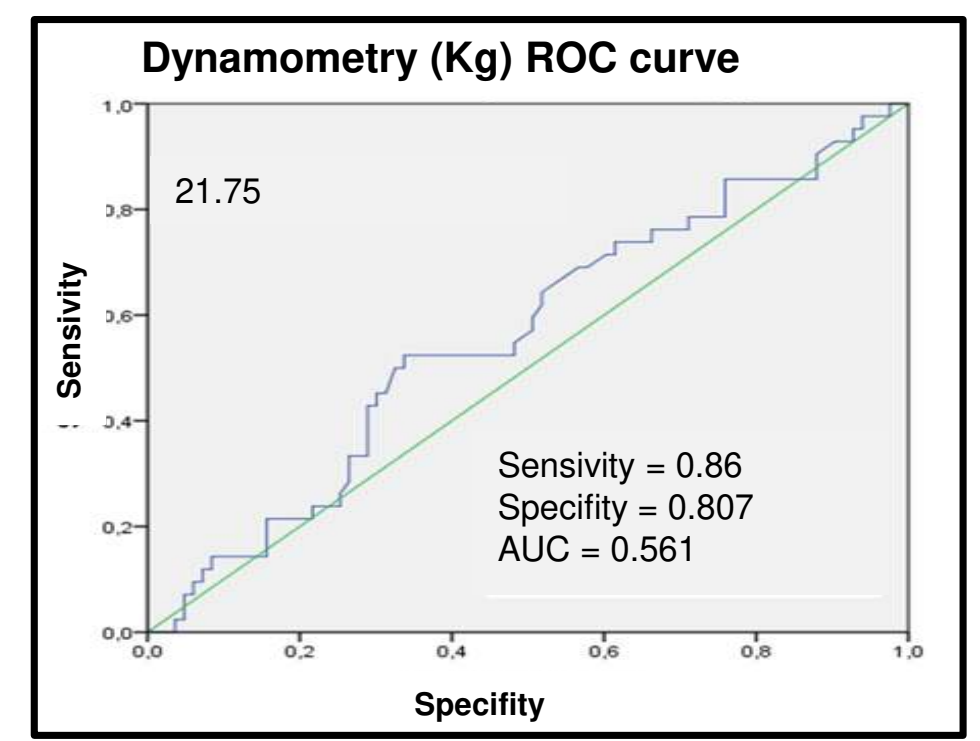

2. The maximal HR in CPR values were significantly higher in woman. These differences disappeared when controlling covariates.

3. Also \%EMHR was significantly higher in women, and this difference remained when controlling covariates.

4. There are not significant differences by sex in maximal PE (Table 2).

CONCLUSIONS

The effort required to perform three CPR minutes does not imply a great physical demand.
Table 1. Demographic, anthropometric and muscular fitness variables of study population, by sex.

\begin{tabular}{|c|c|c|c|c|}
\hline & $\begin{array}{l}\text { Total } \\
(\mathrm{n}=125)\end{array}$ & $\begin{array}{l}\text { Men } \\
\text { ( } n=24)\end{array}$ & $\begin{array}{l}\text { Women } \\
(n=101)\end{array}$ & $\mathbf{P}$ \\
\hline Age (years) & $20.8(3.05)$ & $22.04(4.6)$ & $20.4(2.5)$ & 0.022 \\
\hline Body mass index $\left(\mathrm{kg} / \mathrm{m}^{2}\right)$ & $22.7(4.2)$ & $24.2(5.1)$ & $22.3(3.9)$ & 0.045 \\
\hline \multicolumn{5}{|l|}{ Weight status (\%) } \\
\hline Underweight & 9.6 & 4.2 & 10.9 & 0.315 \\
\hline Normal weight & 72 & 70.8 & 72.3 & 0.887 \\
\hline Overweight & 12 & 8.3 & 12.9 & 0.539 \\
\hline Obesity & 6.4 & 16.7 & 4 & 0.022 \\
\hline Handgrip dynamometry & $27.4(7.9)$ & $40.2(6.9)$ & $24.3(4.1)$ & $<0.001$ \\
\hline
\end{tabular}

Table 2. Maximal heart rate, percentage of maximal heart rate and maximal perceived exertion in three CPR minutes.

\begin{tabular}{|l|l|l|l|l|l|}
\hline & $\begin{array}{l}\text { Total } \\
(n=125)\end{array}$ & $\begin{array}{l}\text { Men } \\
(n=24)\end{array}$ & $\begin{array}{l}\text { Women } \\
(n=101)\end{array}$ & $P$ & $p$ \\
\hline Maximal heart rate in CPR & $142(20.9)$ & $126(13.6)$ & $146(20.6)$ & $<0.001$ & 0.962 \\
\hline
\end{tabular}
\begin{tabular}{|l|l|l|l|l|l|l|l|l|l|l|l|l|l|}
\hline Percentage of maximal heart rate in & $71(10.45)$ & $64(7.01)$ & $73(10.37)$ & $<.001$ & 0.001
\end{tabular} $\mathrm{CPR}^{\mathrm{a}}$

\begin{tabular}{|l|l|l|l|l|l|}
\hline Maximal perceived exertion in CPR & $14.1(1.81)$ & $13.95(2.24)$ & $14.12(1.71)$ & 0.734 & 0.287 \\
\hline
\end{tabular} manoeuvres $^{b}$

Values are means \pm standard deviation, except for percentage of maximal heart rate (\%).
apercentage of maximal heart rate in cardiopulmonary resuscitation (CPR) were calculated with the aPercentage of maximal heart rate in cardiopulmonary
theoretical maximal heart rate values and CPR test.

theoretical maximal heart rate values and CPR test. bMaximal
Scale).
In bold

In bold type: $P \leq 0.05$.
$p$ letter indicates statistical significance $(P \leq 0.05)$ of sex differences controlling for body mass index, and muscular fitness (dynamometry).

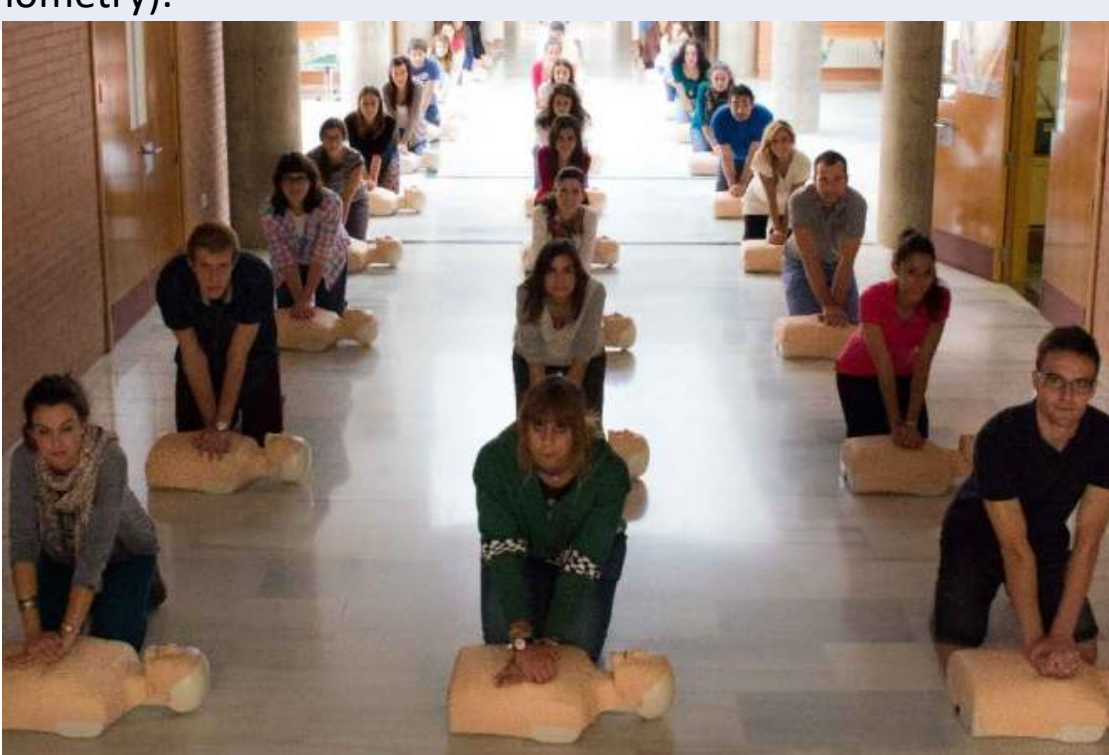

